ОПТИЧНА ПОЛЯРИЗАЦЙНА АНІЗОТРОПІЯ,
ВНУТРІШНІЙ ЕФЕКТ ШТАРКА КВАНТОВОГО
КОНФАЙНМЕНТУ І ВПЛИВ КУЛОНІВСЬКИХ
ЕФЕКТІВ НА ЛАЗЕРНІ ХАРАКТЕРИСТИКИ
[0001]-ОРІЄНТОВАНИХ GaN $/ \mathrm{Al}_{0,3} \mathrm{Ga}_{0,7} \mathrm{~N}$
КВАНТОВИХ ЯМ

\title{
л.о. локоть
}

Інститут фізики напівпровідників ім. В.Є. Лашкарьова НАН України, відділ теоретичної фізики

УдК 533.9

(C) 2012

(Просn. Науки, 41, Kü̈в 03028; e-mail: llokot@gmail.com)

\begin{abstract}
У цій статті представлено теоретичне дослідження просторово розділених електронних і діркових розподілів, яке відображається у самоузгодженому розв'язанні рівнянь Шредінгера для електронів та дірок і рівняння Пуассона. Результати проілюстровано для $\mathrm{GaN} / \mathrm{Al}_{0,3} \mathrm{Ga}_{0,7} \mathrm{~N}$ квантової ями. Спектр оптичного підсилення в [0001]-орієнтованої $\mathrm{GaN} / \mathrm{Al}_{0,3} \mathrm{Ga}_{0,7} \mathrm{~N}$ квантової ями обчислено в ультрафіолетовій області. Знайдено, що як матричні елементи оптичних переходів з важкої діркової підзони в зону провідності, так і спектр оптичного підсилення мають строго $x$ (або $y$ ) поляризацію світла. Показано вплив конфайнменту хвильових функцій на оптичне підсилення, яке неявно залежить від вбудованого електричного поля, що обчислене і дорівнює 2,3 MВ/см. Якщо структури з вузькою шириною ями проявляють звичайну залежність розвитку максимуму підсилення світла майже без зміщення спектральної області, то значного голубого зміщення максимуму підсилення зі зростанням густини плазми набувають структури зі значною шириною квантової ями. Це голубе зміщення відносять до взаємодії між екрануючим п'єзоелектричним полем, створеним деформацією і зонною структурою. Велике зоммерфельдівське або кулонівське підсилення присутнє у квантовій ямі.
\end{abstract}

\section{1. Вступ}

Прямі широкозонні нітридні напівпровідники, які Ірунтуються на $\mathrm{GaN}$ і його сплавах, привертають все більшу увагу внаслідок їх застосування в оптоелектронних приладах, таких як світлові емітерні діоди і лазери від зеленої до ультрафіолетової області спектра, а також ультрафіолетові фотодетектори $[1,2]$.
Світлові емітерні діоди [3-8] і лазерні діоди [9-13] вже було продемонстровано. Реалізація світлових емітерних діодів, що грунтуються на напівпровідниках, ширина забороненої зони яких знаходиться в глибокій ультрафіолетовій області, забезпечує компактні, високоефективні джерела світла для різних застосувань, наприклад, у біологічних детекторах і пристроях збереження інформації [3]. Отже, ці структури перебувають у стадії розвитку.

$\mathrm{У}$ цій статті подано теоретичне дослідження внутрішньої взаємодії електронно-діркової плазми із вбудованим електричним полем. 3 цією метою виконано обчислення зонної структури квантової ями, використовуючи метод інваріантів і апроксимацію огинаючих хвильових векторів. Ми розглядаємо квантову яму $\mathrm{GaN}$ шириною $w$, яка перпендикулярна до напрямку вирощення (0001) і локалізована у $-w / 2<$ $z<w / 2$ просторовій області. У GaN/AlGaN структурі квантової ями присутнє електричне поле індуковане деформацією. Це п'єзоелектричне поле, яке перпендикулярне до площини квантової ями (тобто напрямлене у $z$ напрямку) може бути значним, внаслідок великих п'єзоелектричних сталих $\hat{e}$ у в'юрцитних структурах.

Конфайнмент хвильових функцій значно впливає на оптичне підсилення, яке спостережено з неявною залежністю від вбудованого електричного поля, яке обчислене у структурі і дорівнює $2,3 \mathrm{MB} / \mathrm{cm}$. Такі поля присутні в $\mathrm{GaN} / \mathrm{Al}_{0,3} \mathrm{Ga}_{0,7} \mathrm{~N}$ системах як наслідок деформацій, що індукуються неузгодженостями 
граток матеріалу ями і бар'єра. Величина п'єзоелектричних ефектів чутлива до ширини квантової ями і густини плазми. У цій статті наводимо теоретичне дослідження просторового розділення електронного і діркового розподілів, яке відображається в самоузгодженому розв'язанні рівнянь Шредінгера для електронів і дірок та рівняння Пуассона. Рівняння Пуассона містить потенціал Хартрі, який враховує просторовий розподіл зарядової густини для електронів і дірок. Деталі зонної структури включено в розгляд, оскільки ми порівнюємо різні структури квантової ями. Також обговорюється у статті трактування ефекту Штарка квантового конфайнменту (ЕШКК) в обчисленнях зонної структури у висококонцентраційному режимі.

Порівнюючи спектр підсилення для двох $\mathrm{GaN} / \mathrm{AlGaN}$ структур квантової ями 3 різною шириною ями, ми показуємо взаємодію зонної структури і п'єзоелектричного поля. Зокрема ми бачимо, що в широкій структурі квантової ями, де ЕШКK є важливим, значне голубе зміщення максимуму підсилення, тоді як структури з вузькою шириною ями проявляють звичайну залежність розвитку максимуму підсилення світла майже без зміщення спектральної області. Схоже голубе зміщення екситонного резонансу також спостерігали i проаналізували на мікроскопічному рівні для GaInN/GaN систем квантової ями [14]. Результати [14] відображають збурення компенсації між власною енергією і внеском перенормування поля до мікроскопічної міжзонної поляризації, викликане реальним просторовим розподілом зарядів. Така особливість є у даній квантовій ямі, що непритаманно для GaAs квантової ями внаслідок відсутності п'єзоелектричного поля. Врахування кулонівського перенормування матричних елементів електричного дипольного моменту у двозонній моделі структури квантової ями спричиняє зміну в силі осциляторів зі зміною густини носіїв і конфігурації квантової ями.

У статті [15] було наведено як матричні елементи дипольного моменту міжзонних переходів, так і оптичне підсилення здеформованої в'юрцитної GaN квантової ями без урахування внутрішнього вбудованого п'єзоелектричного поля у структурі квантової ями.

У статті [16] було досліджено лазерне підсилення для AlGaN в'юрцитної квантової ями. Спектр оптичного підсилення для неї обчислено одночасно діагоналізуючи $k p$ гамільтоніан і розв'язуючи рівняння Пуассона. Однак значного зміщення максимуму підсилення зі зростанням густини плазми у межах єдиної структури не було отримано в публікації. Це свідчить про те, що у даній структурі у висококонцентраційному режимі ЕШКК незначний. Цей результат збігається з нашими обчисленнями підсилення, яке подано на рис. 5.

У статті [17] наведено самоузгоджене обчислення оптичного підсилення у псевдоморфічно здеформованій квантовій ямі $\mathrm{GaN}$ як функція густини носіїв. Однак у статті не було враховано перенормування спектра і електричного дипольного моменту, викликаних електрон-електронною і електрон-дірковою кулонівськими кореляціями.

Розуміння впливу зонної структури і ЕШКК на лазерні властивості підсилення допомагає удосконалити лазерні характеристики і оптимальні конфігурації приладу.

Спектр підсилення світла, який наведено у статті, відображає лише строго TE ( $x$ або $y)$ поляризацію світла. Це свідчить про те [18-22], що спектр валентної зони в Г точці походить 3 шестикратно виродженого стану $\Gamma_{15}$. Під дією гексагонального кристалічного поля і спін-орбітальної взаємодії у в'юрцитному кристалі $\Gamma_{15}$ розщеплюється, формуючи три вироджених за спіном рівні: $\Gamma_{9}$, верхній $\Gamma_{7}, \mathrm{i}$ нижній $\Gamma_{7}$ рівні.

$\mathrm{y}$ розділі 2 для опису процесів випромінювання $\mathrm{i}$ поглинання обчислено енергії, а також хвильові функції найнижчої зони провідності та валентних підзон. Залежності від ширини квантової ями, а також густини зарядів як матричних елементів електричного дипольного моменту, так і спектра підсилення світла отримано в $\mathrm{GaN}$ квантовій ямі. У розділі 3 описано хартрі-фоківський спектр підсилення, матричні елементи дипольного моменту міжзонних переходів, які обчислено за теорією, описаною у розділі 2. Порівнюючи спектр підсилення світла для двох квантових ям $\mathrm{GaN} / \mathrm{AlGaN} 3$ різною шириною ями, показуємо взаємодію зонної структури, поляризаційного поля і густини зарядів. Знайдено червоне перенормування спектра підсилення, викликане електрон-електронною і дірково-дірковою кулонівською взаємодією. Знайдено, що зоммерфельдівське підсилення становить 26,7 відсотків відносно величини підсилення, яке отримується в задачі Хартрі. Це підсилення електричного дипольного моменту зумовлене електрон-дірковою кулонівською взаємодією притягання.

\section{2. Теорія}

Ми розглядаємо ЕШКК у здеформованій в'юрцитній $\mathrm{GaN} / \mathrm{Al}_{0,3} \mathrm{Ga}_{0,7} \mathrm{~N}$ квантовій ямі шириною 2,6 нм і 3,9 
нм, в якій висота бар'єра - скінченна, постійна величина для електронів і дорівнює $U_{0}=490 \mathrm{меВ.}$ Теоретичний аналіз розгляду оптичного підсилення здеформованого в'юрцитного квантовоямного лазера грунтується на самоузгодженому розв'язанні рівняння Шредінгера для електронів і дірок у квантовій ямі, шириною $w$ з урахуванням ефекту Штарка і рівняння Пуассона. Рівняння Пуассона містить потенціал Хартрі, який враховує густину зарядів для дірок і електронів. Всі дослідження проведено для температури $300 \mathrm{~K}$.

Перший енергетичний рівень електрона у квантовій ямі, шириною $w$ дорівнюе [23]:

$E_{1}=\frac{2 \xi^{2} \hbar^{2}}{m w^{2}}$

де $m=0,19, m_{0}$ - ефективна маса електрона, $\xi$ знайдено з рівняння

$\cos \xi= \pm \gamma \xi$

де $\gamma=\frac{\hbar}{w} \sqrt{\frac{2}{m U_{0}}}, \tan \xi>0, \xi=\frac{k_{0} w}{2}$. Для $k_{0}$ виконується рівність

$\arcsin \frac{\hbar k_{0}}{\sqrt{2 m U_{0}}}=\frac{n \pi-k_{0} w}{2}$.

Хвильова функція електронів першого енергетичного рівня з урахуванням ЕШКК [24]:

$\Psi(\mathbf{r})=\frac{1}{\sqrt{A}} e^{i k_{t} \rho} \Psi(z, \beta)|S\rangle\left|\sigma_{c}\right\rangle$,

де

$\Psi(z, \beta)=\left\{\begin{array}{l}\psi_{1}(z, \beta) \\ \psi(z, \beta) \\ \psi_{2}(z, \beta)\end{array}\right.$,

де $\psi_{1}(z, \beta)=C_{1} e^{\left(\kappa_{0}-\beta\right)\left(z+\frac{w}{2}\right)}, \quad \psi(z, \beta)=$ $C \sin \left(k_{0} z+\delta_{0}\right) e^{-\beta z}, \quad \psi_{2}(z, \beta)=C_{2} e^{-\left(\kappa_{0}+\beta\right)\left(z-\frac{w}{2}\right)}$. 3 граничних умов $\left.[23,24] \quad \psi_{1}(z, \beta)\right|_{z=-w / 2}=$ $\left.\psi(z, \beta)\right|_{z=-w / 2},\left.\quad \psi_{2}(z, \beta)\right|_{z=w / 2}=\left.\psi(z, \beta)\right|_{z=w / 2}$, $\left.\frac{\psi_{1}^{\prime}(z, \beta)}{\psi_{1}(z, \beta)}\right|_{z=-w / 2}=\left.\frac{\psi^{\prime}(z, \beta)}{\psi(z, \beta)}\right|_{z=-w / 2},\left.\quad \frac{\psi_{2}^{\prime}(z, \beta)}{\psi_{2}(z, \beta)}\right|_{z=w / 2}=$ $\left.\frac{\psi^{\prime}(z, \beta)}{\psi(z, \beta)}\right|_{z=w / 2}, \quad$ можна знайти $C_{1}=$ $C \sin \left(-\frac{k_{0} w}{2}+\delta_{0}\right) e^{\beta \frac{w}{2}}, \quad C_{2}=C \sin \left(\frac{k_{0} w}{2}+\delta_{0}\right) e^{-\beta \frac{w}{2}}$, $\kappa_{0}=k_{0}\left(\frac{1-\cos k_{0} w}{\sin k_{0} w}\right), \delta_{0}=\frac{k_{0} w}{2}+\arctan \frac{\kappa_{0}}{k_{0}}$, де A - площа квантової ями в $x y$ площині, $\rho$ - двовимірний вектор в $x y$ площині, $k_{t}=\left(k_{x}, k_{y}\right)$ хвильовий вектор у цій площині. Сталий множник $C$ можна знайти з умови нормування:

$\int_{-\infty}^{\infty}|\Psi(z, \beta)|^{2} d z=1$.
У такій формі запису хвильової функції (4) відображається інформація, що зоні провідності відповідає представлення $\Gamma_{7}$, що виникло внаслідок розщеплення кристалічним полем $3 \Gamma_{1}, C_{6 v}^{4}$ просторової групи, тобто хвильові функції зони провідності походять 3 $S$ атомних орбіталей. Це важливо при виведенні матричних елементів електричного дипольного моменту, використовуючи теорему Вігнера-Еккарта.

Сильна неузгодженність граток у $\mathrm{GaN}$ i $\mathrm{Al}_{0,3} \mathrm{Ga}_{0,7} \mathrm{~N}$ приводить до внутрішніх деформацій у шарі GaN. У нецентросиметричних структурах внутрішні деформації можуть індукувати макроскопічне вбудоване поляризаційне поле. Цей феномен також описується деформацією, що індукує електричне поле. Відомо, що це п'єзоелектричне поле, яке перпендикулярне до площини квантової ями, може бути значне, оскільки великі п'єзоелектричні сталі у в'юрцитних структурах пов'язані:

$E=-\frac{4 \pi}{\kappa}\left(2\left(e_{31}-e_{33} \frac{C_{13}}{C_{33}}\right) \epsilon_{x x}+P_{\mathrm{sp}}\right)$

де $\hat{e}$ - п'єзотензор, $P_{\mathrm{sp}}$ - спонтанна поляризація, $\hat{\epsilon}$ - деформаційний тензор, $C_{13}, C_{33}$ - еластичні сталі, $\kappa$ - діелектрична проникливість основного матеріалу. Обчислено вбудоване п'єзоелектричне поле в $\mathrm{GaN} / \mathrm{Al}_{0,3} \mathrm{Ga}_{0,7} \mathrm{~N}$ структурі квантової ями 3 виразу (7) і знайдено $E \simeq 0,23 \cdot 10^{7} \mathrm{~B} / \mathrm{cm}$.

Ми припускаємо $[17,25,26]$ такі величини для сталих: $C_{13}=106$ ГПа, $C_{33}=398$ ГПа, $e_{31}=-0,44 \cdot 10^{8}$ $\mathrm{B} / \mathrm{cm}, e_{33}=0,66 \cdot 10^{8} \mathrm{~B} / \mathrm{cm}, P_{\mathrm{sp}}=-0,26 \cdot 10^{7} \mathrm{~B} / \mathrm{cm}$. Поперечні компоненти двоосьової деформації пропорційні різниці між сталими граток матеріалу ями і бар'єра і залежать від вмісту $\mathrm{Al}: x, \epsilon_{x x}=\epsilon_{y y}=$ $\frac{a_{\mathrm{Al}_{x} \mathrm{Ga}_{1-x} \mathrm{~N}}-a_{\mathrm{GaN}}}{a_{\mathrm{GaN}}}, a_{\mathrm{Al}_{x} \mathrm{Ga}_{1-x} \mathrm{~N}}=a_{\mathrm{GaN}}+x\left(a_{\mathrm{AlN}}-a_{\mathrm{GaN}}\right)$; $a_{\mathrm{GaN}} \stackrel{a_{\mathrm{GaN}}}{=} 0,31892 \mathrm{нм}, a_{\mathrm{AlN}}=0,3112$ нм. Поздовжня компонента деформації виражається через еластичні сталі і поперечну компоненту деформації: $\epsilon_{z z}=$ $-2 \frac{C_{13}}{C_{33}} \epsilon_{x x}$.

Можна знайти функціонал, який побудовано з (4), (5) у формі

$J(\beta)=\frac{\langle\Psi|\hat{H}| \Psi\rangle}{\langle\Psi \mid \Psi\rangle}$,

де

$H=H_{c}-\frac{\hbar^{2}}{2 m_{e}^{z}} \frac{\partial^{2}}{\partial z^{2}}+V(z)$,

де $V(z)=U(z)+e \Phi(z)$,

$H_{c}=E_{g}+\Delta_{1}+\Delta_{2}+$ 
$+\frac{\hbar^{2}}{2 m_{e}^{\perp}} k_{t}^{2}+a_{c z} \epsilon_{z z}+a_{c \perp}\left(\epsilon_{x x}+\epsilon_{y y}\right)$,

$m_{z, \perp}^{(c)}=0,19 m_{0}, a_{c z, \perp}=-4080 \mathrm{меB}$ [30]. $U(z)$ можна подати в формі

$U=\left\{\begin{array}{l}U_{0}-\frac{e E w}{2}, z \in(-\infty . .-w / 2) \\ e E z, z \in[-w / 2 \ldots w / 2] \\ U_{0}+\frac{e E w}{2}, z \in(w / 2 \ldots \infty)\end{array}\right.$

Для врахування п'єзоелектричних ефектів модифікуємо рівняння Шредінгера для електронів і дірок, включаючи недіагональний внесок до електронного і діркового гамільтоніана. Рівняння Шредінгера для безмежно глибокої квантової ями з урахуванням ЕШKK і Хартрі потенціалу, який породжений просторово розділеними електронами і дірками, може бути подане у формі

$\hat{H} \Psi_{\nu}(\mathbf{r})=E_{\nu} \Psi_{\nu}(\mathbf{r})$,

де $\hat{H}=\hat{H}_{+}+e E z+e \Phi(z)$. Вводимо блохівську функцію записану як вектор у тривимірному блохівському просторі:

$\left|\alpha \sigma_{v} k_{t}\right\rangle=\left\|\begin{array}{c}\phi_{\alpha}^{(1)}\left(z, k_{t}\right) \\ \phi_{\alpha}^{(2)}\left(z, k_{t}\right) \\ \phi_{\alpha}^{(3)}\left(z, k_{t}\right)\end{array}\right\| \begin{aligned} & \left|1, \sigma_{v}\right\rangle \\ & \left|2, \sigma_{v}\right\rangle \\ & \left|3, \sigma_{v}\right\rangle\end{aligned}$,

де

$\phi_{\alpha}^{(j)}=\sum_{i=1}^{n} V_{k_{t}}^{(j)}[i, \alpha] \chi_{i}(z)$,

i $j=1,2,3$. Блохівський вектор $\alpha$-типу дірки зі спіном $\sigma_{v}= \pm$ i квазіімпульсом $k_{t}$ визначається трьома координатами $\left[V_{k_{t}}^{(1)}[n, \alpha], V_{k_{t}}^{(2)}[n, \alpha], V_{k_{t}}^{(3)}[n, \alpha]\right]$ у базисі $\left[\left|1, \sigma_{v}\right\rangle,\left|2, \sigma_{v}\right\rangle,\left|3, \sigma_{v}\right\rangle\right]$. Огинаюча $z$-залежна частина власних функцій квантової ями може бути визначена 3 граничних умов $\chi_{n}(z=-w / 2)=\chi_{n}(z=w / 2)=0$ безмежно глибокої квантової ями як

$\chi_{n}(z)=\sqrt{\frac{2}{w}} \sin \left(\pi n\left(\frac{z}{w}+\frac{1}{2}\right)\right)$,

де $n$ - натуральне число. Хвильову функцію дірки можна записати у вигляді

$\Psi_{\nu}^{v \sigma_{v}}(\mathbf{r})=\frac{e^{i k_{t} \rho}}{\sqrt{A}}\left|\alpha \sigma_{v} k_{t}\right\rangle$,

де $\nu=\left\{k_{t}, \alpha\right\}$, у наближенні огинаючих хвильових векторів: наближення, в якому розглядають хвильову функцію як добуток огинаючої частини $\chi(z) e^{i k_{t} \rho}$ на періодичний блохівський множник. Блохівські вектори в методі огинаючих хвиль є проекціями точного блохівського вектора на підпростір векторів із симетрією, притаманною Г точці [27]. Це твердження формульно записане у (13), (14):

$H_{ \pm}=\left\|\begin{array}{ccc}F & K_{t} & \mp i H_{t} \\ K_{t} & G & \Delta \mp i H_{t} \\ \pm i H_{t} & \Delta \pm i H_{t} & \lambda\end{array}\right\|$

у базисі $\left[\left|1, \sigma_{v}\right\rangle,\left|2, \sigma_{v}\right\rangle,\left|3, \sigma_{v}\right\rangle\right][28]$, де

$F=\Delta_{1}+\Delta_{2}+\lambda+\theta$

$G=\Delta_{1}-\Delta_{2}+\lambda+\theta$

$\lambda=\lambda_{k}+\lambda_{\epsilon}$

$\theta=\theta_{k}+\theta_{\epsilon}$

$\lambda_{k}=\frac{\hbar^{2}}{2 m_{0}}\left(A_{1} k_{z}^{2}+A_{2} k_{t}^{2}\right)$

$\lambda_{\epsilon}=D_{1} \epsilon_{z z}+D_{2}\left(\epsilon_{x x}+\epsilon_{y y}\right)$,

$\theta_{k}=\frac{\hbar^{2}}{2 m_{0}}\left(A_{3} k_{z}^{2}+A_{4} k_{t}^{2}\right)$

$\theta_{\epsilon}=D_{3} \epsilon_{z z}+D_{4}\left(\epsilon_{x x}+\epsilon_{y y}\right)$,

$K_{t}=\frac{\hbar^{2}}{2 m_{0}}\left(A_{5} k_{t}^{2}\right)$

$H_{t}=\frac{\hbar^{2}}{2 m_{0}}\left(A_{6} k_{t} k_{z}\right)$

$\Delta=\sqrt{2} \Delta_{3}$,

$k_{t}^{2}=k_{x}^{2}+k_{y}^{2}$

$|1, \pm\rangle=\frac{1}{\sqrt{2}}\left[|1,1\rangle|\uparrow\rangle e^{\frac{-3 i \varphi}{2}} e^{-\frac{3 i \pi}{4}} \pm|1,-1\rangle|\downarrow\rangle e^{\frac{3 i \varphi}{2}} e^{\frac{3 i \pi}{4}}\right]$

$|2, \pm\rangle=\frac{1}{\sqrt{2}}\left[ \pm|1,1\rangle|\downarrow\rangle e^{\frac{-i \varphi}{2}} e^{-\frac{i \pi}{4}}+|1,-1\rangle|\uparrow\rangle e^{\frac{i \varphi}{2}} e^{\frac{i \pi}{4}}\right]$

$|3, \pm\rangle=\frac{1}{\sqrt{2}}\left[ \pm|1,0\rangle|\uparrow\rangle e^{\frac{-i \varphi}{2}} e^{-\frac{i \pi}{4}}+|1,0\rangle|\downarrow\rangle e^{\frac{i \varphi}{2}} e^{\frac{i \pi}{4}}\right]$

$|1,1\rangle=-\frac{1}{\sqrt{2}}|X+i Y\rangle$ 


$$
|1,0\rangle=|Z\rangle, \quad \Delta_{2}=\Delta_{3} .
$$

$|1,-1\rangle=\frac{1}{\sqrt{2}}|X-i Y\rangle$.

Структура валентних підзон $E_{\alpha}^{\sigma v}\left(k_{t}\right)$ може бути визначена при розв'язку системи рівнянь:

$$
\sum_{j=1}^{3}\left(H_{i j}^{\sigma_{v}}\left(k_{z}=-i \frac{\partial}{\partial z}\right)+\delta_{i j} E_{\alpha}^{\sigma_{v}}\left(k_{t}\right)\right) \phi_{\alpha}^{(j) \sigma_{v}}\left(z, k_{t}\right)=0,
$$

де $i=1,2,3$. У квазікубічній апроксимації параметри ефективної маси і деформаційного потенціалу зв'язані у вигляді $[19,21]$ :

$$
\begin{aligned}
& 4 A_{5}-\sqrt{2} A_{6}=A_{3}, \quad 2 A_{4}=-A_{3}=A_{1}-A_{2}, \\
& 4 D_{5}-\sqrt{2} D_{6}=D_{3}, \quad 2 D_{4}=-D_{3}=D_{1}-D_{2},
\end{aligned}
$$

Ми припускаємо в обчисленнях для параметрів ефективної маси валентної зони [29]: $A_{1}=-6,56 ; A_{2}=$ $-0,91 ; A_{3}=5,65 ; A_{4}=-2,83 ; A_{5}=-3,13 ; A_{6}=$ $-4,86$, для деформаційного потенціалу [30]: $D_{1}=700$ меВ, $D_{2}=2100 \mathrm{меВ,} D_{3}=1400$ меВ, $D_{4}=-700$ меВ, для енергетичних параметрів при температурі $300 \mathrm{~K}$ [15, 25]: $E_{g}=3507 \mathrm{meB}, \Delta_{1}=\Delta_{c r}=16 \mathrm{meB}$, $\Delta_{2}=\Delta_{3}=\Delta_{s o} / 3=4$ меВ. Розв'язуючи рівняння Пуассона з умовою $\int_{-\infty}^{\infty} \rho(z) d z=0$ :

$$
\frac{d^{2} \Phi}{d z^{2}}=\frac{4 \pi}{\kappa} \rho(z)
$$

і з вибраними хвильовими функціями, можна знайти розв'язок для потенціалу Хартрі $e \Phi(z)$ :

$$
\begin{aligned}
& e \Phi=\frac{2 e^{2}}{\kappa} \sum_{\alpha, n, k, i} g_{\alpha} \int k_{t} d k_{t}\left\langle v_{i}, \sigma_{v}\left|V_{k_{t}}^{i}[\alpha, n] V_{k_{t}}^{i}[\alpha, k]\right| \sigma_{v}, v_{i}\right\rangle f_{\alpha, p}\left(k_{t}\right)\left\{\begin{array}{l}
w\left(\frac{\cos \pi Z(k+n)}{\pi^{2}(k+n)^{2}}-\frac{\cos \pi Z(n-k)}{\pi^{2}(n-k)^{2}}\right) \\
w\left(\frac{Z^{2}}{2}+\frac{1}{4} \frac{\cos 2 \pi n Z}{\pi^{2} n^{2}}\right)
\end{array}\right. \\
& -\frac{2 e^{2}}{\kappa} g_{1} \int k_{t} d k_{t}\left\langle S\left|\left\langle\sigma_{c}\left|C^{2}\right| \sigma_{c}\right\rangle\right| S\right\rangle f_{1 n}\left(k_{t}\right)\left\{\begin{array}{l}
\frac{1-\cos \left(-k_{0} w+2 \delta_{0}\right)}{2} e^{\beta w \frac{e^{2\left(\kappa_{0}-\beta\right)\left(z+\frac{w}{2}\right)}}{4\left(\kappa_{0}-\beta\right)^{2}}} \\
\frac{e^{-2 \beta z}-\frac{2 \cos 2\left(k_{0} z+\delta_{0}\right) e^{-2 \beta z}}{\left(4 \beta^{2}+4 k_{0}^{2}\right)^{2}}\left(\beta^{2}-k_{0}^{2}\right)+\frac{\sin 2\left(k_{0} z+\delta_{0}\right) e^{-2 \beta z}}{4\left(\beta^{2}+k_{0}^{2}\right)^{2}}}{8 \beta_{0} \beta} \\
\frac{1-\cos \left(k_{0} w+2 \delta_{0}\right)}{2} e^{-\beta w} \frac{e^{-2\left(\kappa_{0}+\beta\right)\left(z-\frac{w}{2}\right)}}{4\left(\kappa_{0}+\beta\right)^{2}}
\end{array}\right.
\end{aligned}
$$

де $Z=\frac{z}{w}+\frac{1}{2}, g_{\alpha}-$ відображає виродження $\alpha$ діркової підзони, $g_{1}$ - відображає виродження першої квантованої зони провідності, $e$ - величина заряду електрона, $\kappa$ - діелектрична проникливість, $f_{\alpha, p}\left(k_{t}\right), f_{1 n}\left(k_{t}\right)-$ розподіли Фермі-Дірака для дірок і електронів. Тут припускаємо концентрації носіїв $9 \cdot 10^{12} \mathrm{~cm}^{-2}$ і $7 \cdot 10^{12}$ $\mathrm{CM}^{-2}$.

Розв'язуючи (12) для дірок у безмежно глибокій квантовій ямі і знаходячи мінімум функціоналу (8) для електронів у квантовій ямі з бар'єрами скінченної висоти, можуть бути знайдені як енергія, так і хвильові функції електронів та дірок, враховуючи просторовий розподіл електронної і діркової зарядової густини у квантовій ямі заданої концентрації у п'єзоелектричному полі. Екрануюче поле визначається здійсненням ітерації (8), (12), (21), поки не досягнеться збіжність розв'язків в обчисленнях зонної стру- ктури. Ми використовуємо для просторового розподілу носіїв найнижчий порядок огинаючих хвильових векторів електронів і дірок.

Розглянемо матричні елементи міжзонних переходів:

$$
M_{j \sigma \rightarrow j^{\prime} \sigma^{\prime}}(\mathbf{k})=\int d^{3} r U_{j^{\prime} \sigma^{\prime} \mathbf{k}} \mathbf{e} \hat{\mathbf{p}} U_{j \sigma \mathbf{k}} .
$$

Хвильові функції валентної зони перетворюються відповідно до представлення $\Gamma_{1}+\Gamma_{5}$, тоді як хвильова функція зони провідності перетворюється відповідно до представлення $\Gamma_{1}$. Для знаходження представлення, відповідно до якого перетворюються $M_{j \sigma \rightarrow j^{\prime} \sigma^{\prime}}(\mathbf{k})$, необхідно розглянути прямий добуток $\Gamma_{1} \times\left(\Gamma_{1}+\Gamma_{5}\right)$. Симетрійні елементи точкової групи $C_{6 v}$ :

$g=E, C_{2}, 2 C_{3}, 2 C_{6}, 3 \sigma_{v}, 3 \sigma_{v}^{\prime}$ 
де $C_{n}$ - вісь $n$ порядку, $3 \sigma_{v}, 3 \sigma_{v}^{\prime}$ - шість площин відбиття, які проходять через вісь шостого порядку. Для цих елементів можна знайти представлення $\Gamma_{1}+\Gamma_{5}$ :

$$
\begin{aligned}
& \chi(E)=3, \chi\left(C_{2}\right)=-1, \chi\left(2 C_{3}\right)=0, \\
& \chi\left(2 C_{6}\right)=2, \chi\left(3 \sigma_{v}\right)=1, \chi\left(3 \sigma_{v}^{\prime}\right)=1 .
\end{aligned}
$$

Квадрати елементів незвідного представлення дорівнюють:

$g^{2}=E, E, C_{3}, C_{3}, E, E$.

Необхідно знайти

$$
\begin{aligned}
& \chi_{\psi}^{2}(E)=9, \chi_{\psi}^{2}\left(C_{2}\right)=1, \chi_{\psi}^{2}\left(2 C_{3}\right)=0, \\
& \chi_{\psi}^{2}\left(2 C_{6}\right)=4, \chi_{\psi}^{2}\left(3 \sigma_{v}\right)=1, \chi_{\psi}^{2}\left(3 \sigma_{v}^{\prime}\right)=1,
\end{aligned}
$$

тоді як

$$
\begin{aligned}
& \chi_{\psi}\left(E^{2}\right)=3, \chi_{\psi}\left(C_{2}^{2}\right)=3, \chi_{\psi}\left(2 C_{3}^{2}\right)=0, \\
& \chi_{\psi}\left(2 C_{6}^{2}\right)=0, \chi_{\psi}\left(3 \sigma_{v}^{2}\right)=3, \chi_{\psi}\left(3 \sigma_{v}^{\prime 2}\right)=3 .
\end{aligned}
$$

Симетричне представлення може бути знайдене у формі

$$
\begin{aligned}
& \frac{1}{2}\left(\chi_{\psi}^{2}(g)+\chi_{\psi}\left(g^{2}\right)\right): \\
& \frac{1}{2}\left(\chi_{\psi}^{2}(E)+\chi_{\psi}\left(E^{2}\right)\right)=6, \\
& \frac{1}{2}\left(\chi_{\psi}^{2}\left(C_{2}\right)+\chi_{\psi}\left(C_{2}^{2}\right)\right)=2, \\
& \frac{1}{2}\left(\chi_{\psi}^{2}\left(2 C_{3}\right)+\chi_{\psi}\left(2 C_{3}^{2}\right)\right)=0, \\
& \frac{1}{2}\left(\chi_{\psi}^{2}\left(2 C_{6}\right)+\chi_{\psi}\left(2 C_{6}^{2}\right)\right)=2, \\
& \frac{1}{2}\left(\chi_{\psi}^{2}\left(3 \sigma_{v}\right)+\chi_{\psi}\left(3 \sigma_{v}^{2}\right)\right)=2, \\
& \frac{1}{2}\left(\chi_{\psi}^{2}\left(3 \sigma_{v}^{\prime}\right)+\chi_{\psi}\left(3 \sigma_{v}^{\prime 2}\right)\right)=2 .
\end{aligned}
$$

Антисиметричні представлення дорівнюють:

$$
\begin{aligned}
& \frac{1}{2}\left(\chi_{\psi}^{2}(g)-\chi_{\psi}\left(g^{2}\right)\right): \\
& \frac{1}{2}\left(\chi_{\psi}^{2}(E)-\chi_{\psi}\left(E^{2}\right)\right)=3, \\
& \frac{1}{2}\left(\chi_{\psi}^{2}\left(C_{2}\right)-\chi_{\psi}\left(C_{2}^{2}\right)\right)=-1, \\
& \frac{1}{2}\left(\chi_{\psi}^{2}\left(2 C_{3}\right)-\chi_{\psi}\left(2 C_{3}^{2}\right)\right)=0, \\
& \frac{1}{2}\left(\chi_{\psi}^{2}\left(2 C_{6}\right)-\chi_{\psi}\left(2 C_{6}^{2}\right)\right)=2, \\
& \frac{1}{2}\left(\chi_{\psi}^{2}\left(3 \sigma_{v}\right)-\chi_{\psi}\left(3 \sigma_{v}^{2}\right)\right)=-1, \\
& \frac{1}{2}\left(\chi_{\psi}^{2}\left(3 \sigma_{v}^{\prime}\right)-\chi_{\psi}\left(3 \sigma_{v}^{2}\right)\right)=-1 .
\end{aligned}
$$

Симетричне представлення можна розкласти на незвідні представлення $2 A_{1}+E_{1}+E_{2}$, тоді як антисиметричне на $A_{2}+E_{1}$. Отже, у в'юрцитний гамільтоніан $H(\epsilon, \mathbf{k})$ повинні входити парні функції (відносно інверсії часу), які перетворюються за $2 A_{1}+E_{1}+E_{2}$, і непарні, які перетворюються за $A_{2}+E_{1}$ [19].
Векторне представлення можна записати

$$
\begin{aligned}
& \chi_{v}(E)=3, \chi_{v}\left(C_{2}\right)=-1, \chi_{v}\left(2 C_{3}\right)=0, \\
& \chi_{v}\left(2 C_{6}\right)=2, \chi_{v}\left(3 \sigma_{v}\right)=1, \chi_{v}\left(3 \sigma_{v}^{\prime}\right)=1
\end{aligned}
$$

і його можна розкласти на незвідні представлення $A_{1}+E_{1}$. А представлення, відповідно до якого перетворюється міжзонний оператор саме можна розкласти на

$\Gamma_{1} \times\left(\Gamma_{1}+\Gamma_{5}\right)=A_{1}+E_{1}$.

Отже, прямий добуток представлення (31) відображає існування ненульових матричних елементів електричного дипольного моменту, оскільки з цього представлення можна сформувати векторне представлення.

Дозволені матричні елементи електричного дипольного моменту $\langle S|\left\langle\sigma_{c}|\mathbf{e} \hat{\mathbf{p}}| v_{i}, \sigma_{v}\right\rangle$ знайдено у вигляді

$$
\begin{aligned}
& \langle S|\left\langle\uparrow|\mathbf{e} \hat{\mathbf{p}}| v_{1}, \pm\right\rangle=-\frac{1}{2} P_{\perp} e^{i \varphi} e^{-i \frac{3 \pi}{4}} \sin \theta, \\
& \langle S|\left\langle\uparrow|\mathbf{e} \hat{\mathbf{p}}| v_{2}, \pm\right\rangle=\frac{1}{2} P_{\perp} e^{-i \varphi} e^{i \frac{\pi}{4}} \sin \theta, \\
& \langle S|\left\langle\uparrow|\mathbf{e} \hat{\mathbf{p}}| v_{3}, \pm\right\rangle= \pm \frac{1}{\sqrt{2}} P_{z} e^{-i \frac{\pi}{4}} \cos \theta \\
& \langle S|\left\langle\downarrow|\mathbf{e} \hat{\mathbf{p}}| v_{1}, \pm\right\rangle= \pm \frac{1}{2} P_{\perp} e^{-i \varphi} e^{i \frac{3 \pi}{4}} \sin \theta, \\
& \langle S|\left\langle\downarrow|\mathbf{e} \hat{\mathbf{p}}| v_{2}, \pm\right\rangle=\mp \frac{1}{2} P_{\perp} e^{i \varphi} e^{-i \frac{\pi}{4}} \sin \theta, \\
& \langle S|\left\langle\downarrow|\mathbf{e} \hat{\mathbf{p}}| v_{3}, \pm\right\rangle=\frac{1}{\sqrt{2}} P_{z} e^{i \frac{\pi}{4}} \cos \theta .
\end{aligned}
$$

Існують лише такі матричні елементи між базисними функціями $[21,23]$ :

$$
\begin{aligned}
& \left\langle S\left|\hat{p}_{z}\right| 1,0\right\rangle=P_{z}, \\
& \left\langle S\left|\hat{p}_{+}\right| 1,-1\right\rangle=-\left\langle S\left|\hat{p}_{-}\right| 1,1\right\rangle=\sqrt{2} P_{\perp},
\end{aligned}
$$

зумовлені симетричними властивостями блохівських функцій, де $\hat{p}_{ \pm}=\hat{p}_{x} \pm i \hat{p}_{y}$. Дві сталі матричного елемента моменту можуть бути визначені як $P_{\perp} \equiv$ $\left\langle S\left|\hat{p}_{x}\right| X\right\rangle$ і $P_{z} \equiv\left\langle S\left|\hat{p}_{z}\right| Z\right\rangle$. У результаті циліндричної симетрії матричні елементи залежать лише від різниці $\varphi=\varphi_{\mathbf{E}}-\varphi_{\mathbf{k}}$ між проекціями на площину кутів векторів $\mathbf{e} \| \mathbf{E} \mathbf{~} \mathbf{k}$. Для спрощення обчислень припускаємо $\varphi_{\mathbf{k}}=0$ і позначимо сферичні кути вектора $\mathbf{e}$ через $\varphi$ і $\theta$ [21]. Розглядаємо випадок, коли хвильовий вектор дірки напрямлений паралельно до осі $c$. У цій ситуації $\varphi=0$ в наших обчисленнях і вектор е у сферичних координатах: е $=(\sin \theta \cos \varphi, \sin \theta \sin \varphi, \cos \theta)$, тоді як ер$\hat{\mathbf{p}}=\frac{1}{2} \sin \theta\left(e^{i \varphi} \hat{p}_{-}+e^{-i \varphi} \hat{p}_{+}\right)+\hat{p}_{z} \cos \theta$. Як відомо з [21], величини сталих $\left|P_{z, \perp}\right|^{2}$ можуть бути знайдені з $k p$-теорії:

$\frac{m_{0}}{m_{z, x}^{(c)}}=1+\frac{2}{m_{0}} \Sigma_{j \neq c} \frac{\left|\left\langle c\left|\hat{p}_{z, x}\right| j\right\rangle\right|^{2}}{E_{c}^{0}-E_{j}^{0}}$ 

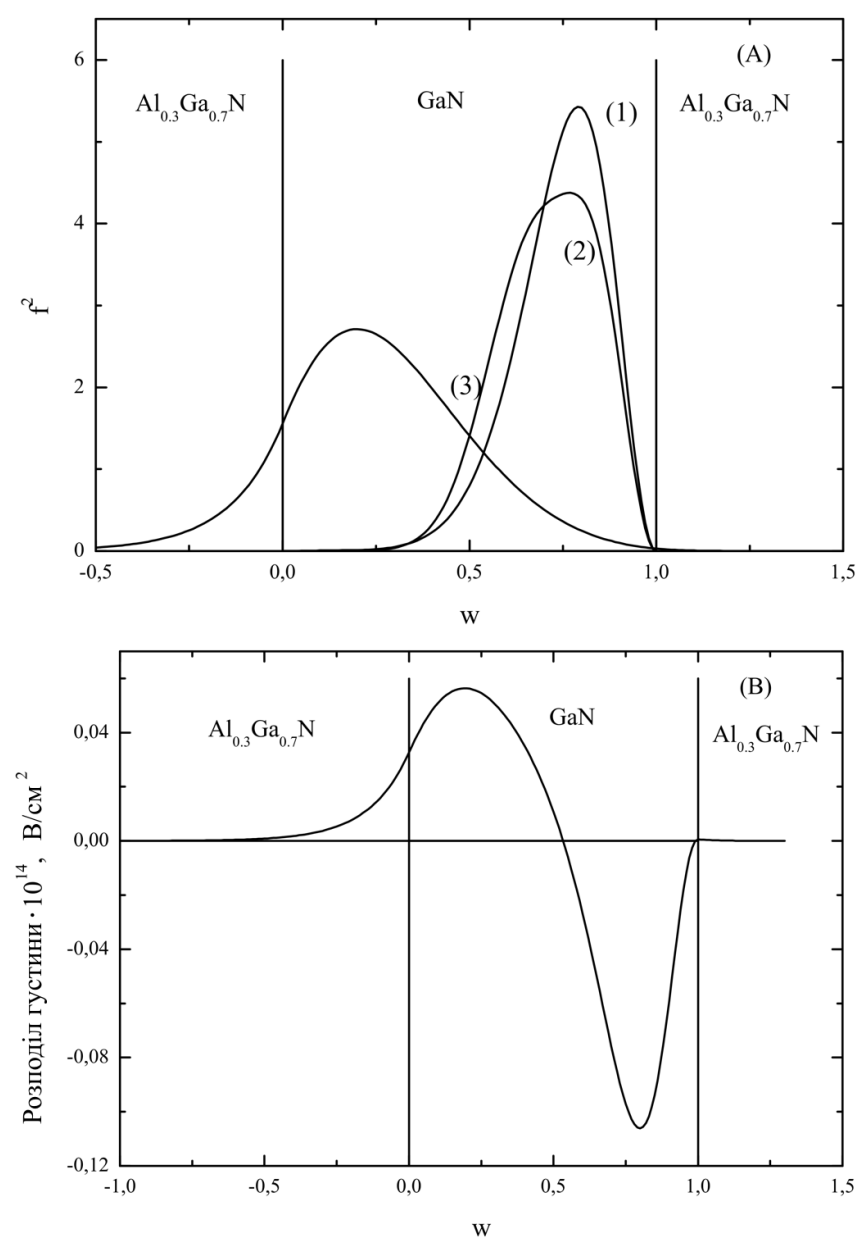

Рис. 1. Обчислений квадрат хвильових функцій важкої дірки (1), легкої дірки (2) при поперечному хвильовому векторі $k_{t}=$ $8 \cdot 10^{6} \mathrm{~cm}^{-1}$, і електрона (3) (А); розподіл густини зарядів на ширині квантової ями (В) для квантової ями, шириною 3,9 нм, при концентрації носіїв $9 \cdot 10^{12} \mathrm{~cm}^{-2}$

і з експериментально вимірювальної ефективної маси зони провідності $m_{z, \perp}^{(c)}=0,19 m_{0}$ і $E_{g}=3,5$ еВ можна оцінити $\frac{2\left|P_{z, \perp}\right|^{2}}{m_{0}} \sim 15 \mathrm{eB}$.

На рис. 3 наведено $k$-залежність матричних елементів квантової ями. Ми бачимо, що матричні елементи мають строго $x$ (або $y$ ) поляризацію світла для переходів з важкої діркової підзони у зону провідності, тоді як для $z$ поляризації світла переходи заборонені [32]. Тому спектр підсилення, поданий на рис. 4, 5, відображає лише підсилення ТЕ поляризованого світла для обох ширин квантової ями. Така поведінка узгоджується з обчисленнями матричних елементів моменту у в'юрцитній $\mathrm{GaN}$ квантовій ямі. Оскільки вершина валентної зони походить $3 \Gamma_{9}, \Gamma_{7}, \Gamma_{7}$ незвідних представлень. Результати, подані на рис. 3-5,
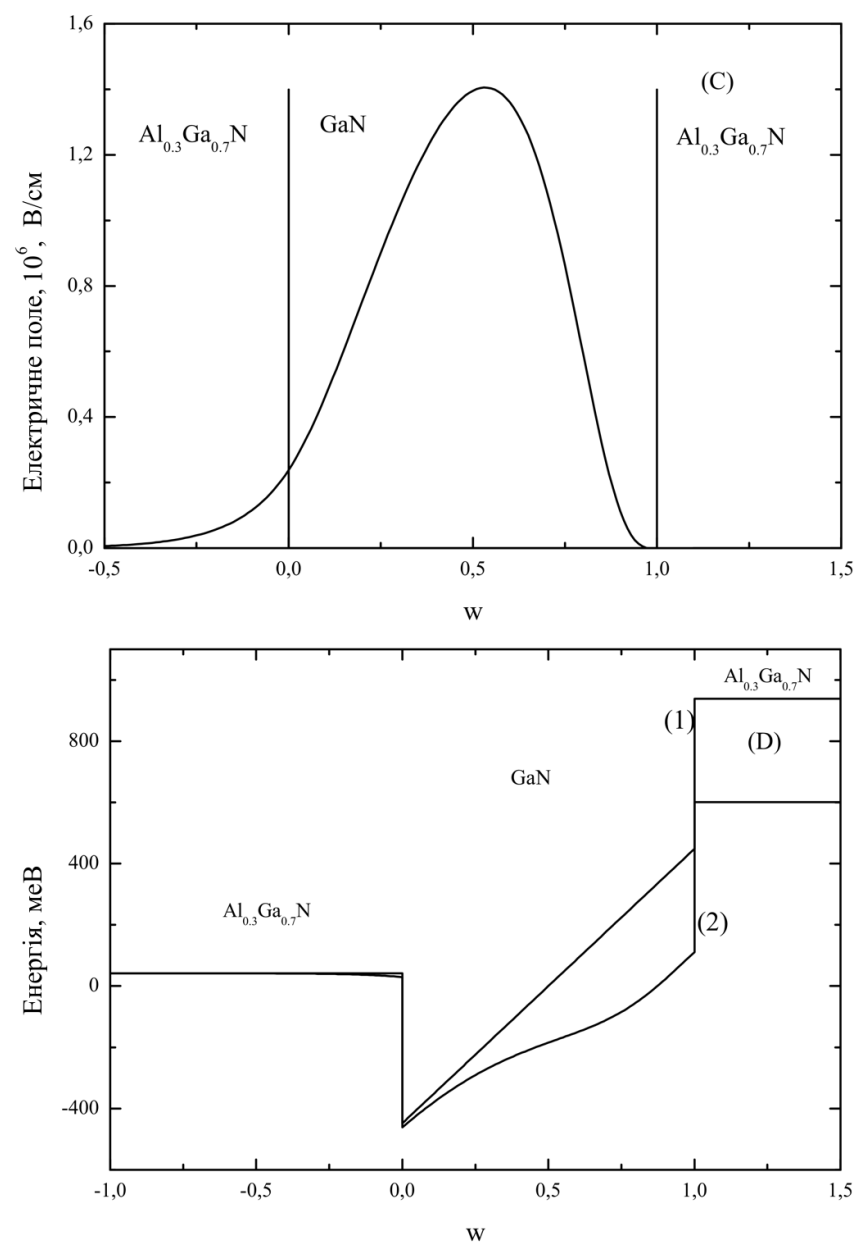

Рис. 2. Розподіл ефективного екрануючого електричного поля (C); потенціал квантової ями (1), і екрануючий потенціал (2) на ширині квантової ями (D) для квантової ями, шириною 3,9 нм, при концентрації носіїв $9 \cdot 10^{12} \mathrm{~cm}^{-2}$

свідчать про оптичну поляризаційну анізотропію матричних елементів електричного дипольного моменту для міжзонних переходів у $\mathrm{GaN} / \mathrm{Al}_{0,3} \mathrm{Ga}_{0,7} \mathrm{~N}$ структуpi квантової ями.

Оптичне підсилення матеріалу $[15,31]$ може бути обчислене із золотого правила Фермі:

$\alpha_{0}=\frac{\pi e^{2}}{c \sqrt{\kappa} m_{0} w \omega} \times$

$\times \sum_{\sigma_{c}=\uparrow, \downarrow} \sum_{\sigma_{v}=+,-} \sum_{m, \alpha} \int k_{t} d k_{t} \int \frac{d \phi}{2 \pi}\left|\hat{\mathbf{e}} M_{m \alpha}^{\sigma_{c} \sigma_{v}}\left(k_{t}\right)\right|^{2} \times$

$\times \frac{\left(f_{m}^{c}\left(k_{t}\right)-f_{\sigma_{v} \alpha}^{v}\left(k_{t}\right)\right)\left(\frac{\hbar \gamma}{\pi}\right)}{\left(E_{\sigma_{v}, m \alpha}^{c v}\left(k_{t}\right)-\hbar \omega\right)^{2}+(\hbar \gamma)^{2}}$, 

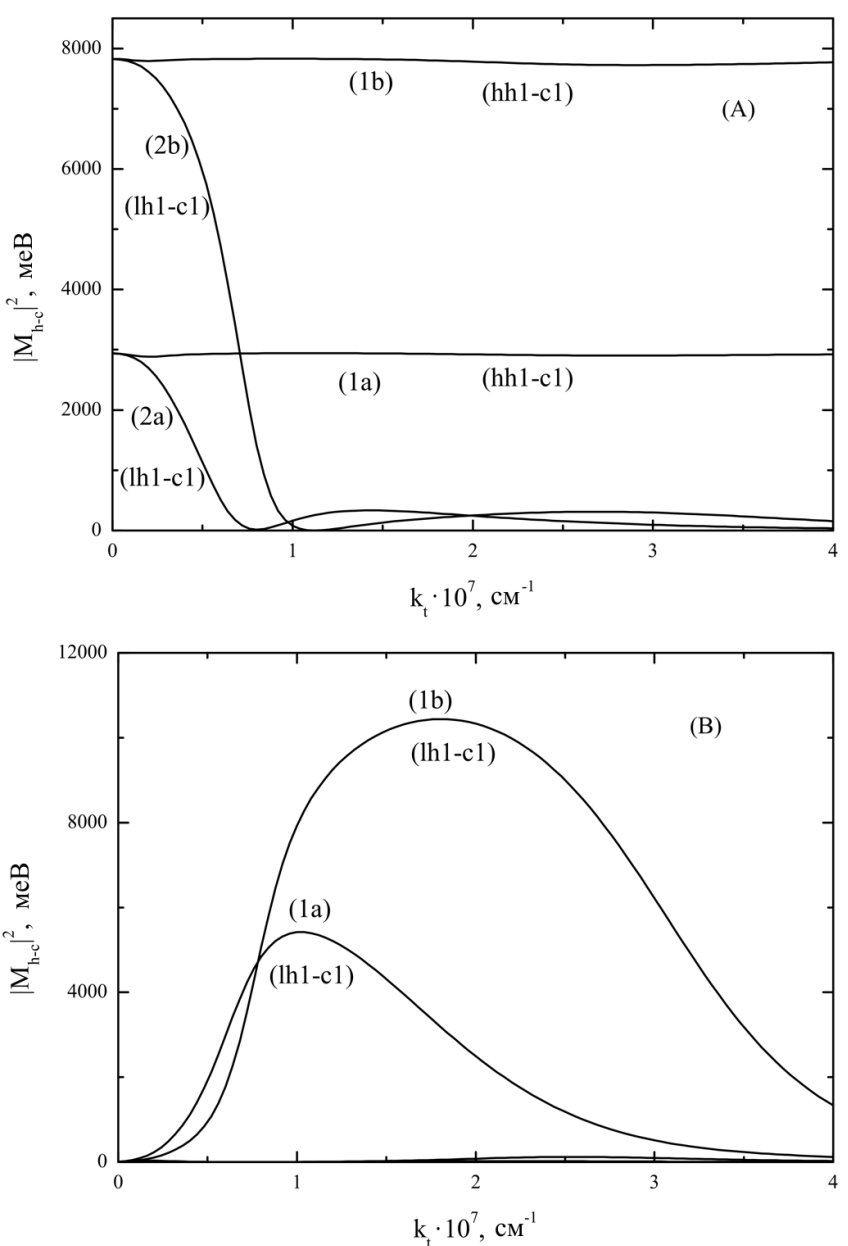

Рис. 3. Матричні елементи моменту для $x$ - (або $y$-) поляризації (А); $z$-поляризації (В): 1а - квантова яма, шириною 3,9 нм, при концентрації $n=p=9 \cdot 10^{12} \mathrm{~cm}^{-2} ; 2 \mathrm{a}-$ квантова яма, шириною 3,9 нм, при концентрації $n=p=7 \cdot 10^{12} \mathrm{~cm}^{-2} ; 1 \mathrm{~b}-$ квантова яма, шириною 2,6 нм, при концентрації $n=p=9 \cdot 10^{12}$ $\mathrm{cm}^{-2} ; 2 \mathrm{~b}$ - квантова яма, шириною 2,6 нм, при концентрації $n=p=7 \cdot 10^{12} \mathrm{~cm}^{-2}$

де $e$ - заряд електрона, $m_{0}$ - маса спокою електрона у просторі, $c$ - швидкість світла у просторі, $\kappa=8,27$ діелектрична проникливість матеріалу, $f_{m}^{c}, f_{\sigma_{v} \alpha}^{v}-$ функції розподілу Фермі-Дірака для електронів у зоні провідності і у валентній зоні, е - одиничний вектор векторного потенціалу електромагнітної хвилі, $E_{\sigma_{v}, m \alpha}^{c v}\left(k_{t}\right)$ - міжзонна енергія зони провідності і валентної зони, і $\hbar \omega-$ оптична енергія, $\hbar \gamma-$ половина ширини хвилі в лоренціанівській функції, що дорівнює 6,56 меВ. Ми розглядаємо електромагнітну хвилю, яка поширюється у площині квантової ями. Підсилення, яке визначає порогову здатність лазера, пропорційне підсиленню матеріалу, що множиться на

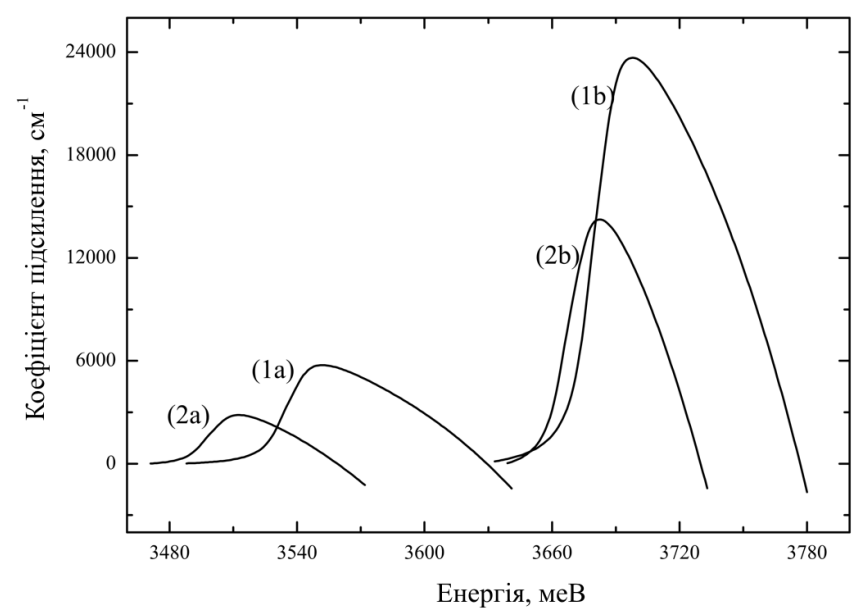

Рис. 4. Обчислений хартрівський спектр підсилення: $1 \mathrm{a}-$ квантова яма, шириною 3,9 нм, при концентрації $n=p=9 \cdot 10^{12}$ $\mathrm{cm}^{-2} ; 2 \mathrm{a}-$ квантова яма, шириною 3,9 нм, при концентрації $n=p=7 \cdot 10^{12} \mathrm{~cm}^{-2} ; 1 \mathrm{~b}-$ квантова яма, шириною 2,6 нм, при концентрації $n=p=9 \cdot 10^{12} \mathrm{~cm}^{-2} ; 2 \mathrm{~b}-$ квантова яма, шириною 2,6 нм, при концентрації $n=p=7 \cdot 10^{12} \mathrm{~cm}^{-2}$

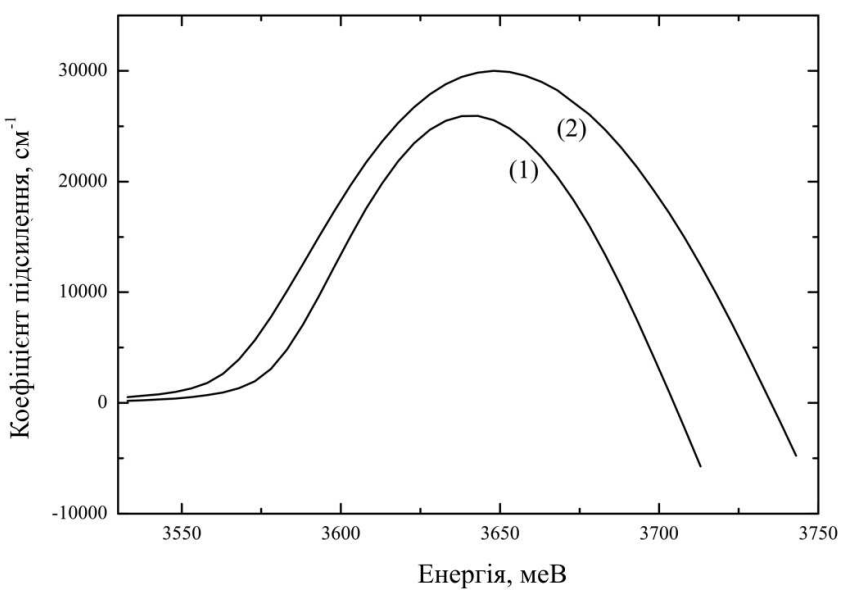

Рис. 5. Обчислений хартрі-фоківський спектр підсилення для квантової ями, шириною 2,6 нм, і при концентраціях $n=p=$ $7 \cdot 10^{12} \mathrm{~cm}^{-2}(1)$ i $n=p=9 \cdot 10^{12} \mathrm{~cm}^{-2}$ (2)

оптичний конфайнментфактор $\Gamma$ і на число $a$ квантових ям у мультиплетних квантових ямах: $\alpha=\alpha_{0} \Gamma$. Ми припускаємо, що Г дорівнює 0,01, $a$ дорівнює 1.

Хоча носії у кожній зоні знаходяться в сильно нерівноважному стані, міжзонні релаксаційні часи набагато більші, ніж міжпідзонні релаксаційні часи. Отже, в обчисленнях використовуємо статистику Фермі-Дірака.

Використовуючи вирази для базисних функцій, отримуємо дві скалярні поляризації - залежності матричних елементів електричного дипольного момен- 
ту. Для ТЕ-поляризації ( $\hat{e}=\hat{x}$ або $\hat{y} \perp c$ осі), тобто для поляризації світла з вектором, який лежить у площині квантової ями:

$$
\begin{aligned}
& \left|\left(M_{x}\right)_{1 \alpha}^{\sigma}\left(k_{t}\right)\right|^{2}= \\
& =\frac{\left|\left\langle S\left|p_{x}\right| X\right\rangle\right|^{2}}{4}\left\{\left\langle\Psi_{1}(\beta) \mid \sum_{n} V_{k_{t}}^{1}[n, \alpha] \chi_{n}\right\rangle^{2}+\right. \\
& \left.+\left\langle\Psi_{1}(\beta) \mid \sum_{n} V_{k_{t}}^{2}[n, \alpha] \chi_{n}\right\rangle^{2}\right\}, \\
& \text { для } \sigma=+, \\
& =\frac{\left|\left\langle S\left|p_{x}\right| X\right\rangle\right|^{2}}{4}\left\{\left\langle\Psi_{1}(\beta) \mid \sum_{n} V_{k_{t}}^{4}[n, \alpha] \chi_{n}\right\rangle^{2}+\right. \\
& \left.+\left\langle\Psi_{1}(\beta) \mid \sum_{n} V_{k_{t}}^{5}[n, \alpha] \chi_{n}\right\rangle^{2}\right\}, \\
& \text { для } \sigma=-.
\end{aligned}
$$

Для ТМ-поляризації $(\hat{e}=\hat{z} \| c$ осі), тобто для поляризації світла з вектором, перпендикулярним до площини квантової ями:

$$
\begin{aligned}
& \left|\left(M_{z}\right)_{1 \alpha}^{\sigma}\left(k_{t}\right)\right|^{2}= \\
& =\frac{\left|\left\langle S\left|p_{z}\right| Z\right\rangle\right|^{2}}{2}\left\{\left\langle\Psi_{1}(\beta) \mid \sum_{n} V_{k_{t}}^{3}[n, \alpha] \chi_{n}\right\rangle^{2}\right\}, \\
& \text { для } \sigma=+, \\
& =\frac{\left|\left\langle S\left|p_{z}\right| Z\right\rangle\right|^{2}}{2}\left\{\left\langle\Psi_{1}(\beta) \mid \sum_{n} V_{k_{t}}^{6}[n, \alpha] \chi_{n}\right\rangle^{2}\right\},
\end{aligned}
$$

для $\sigma=-$.

\section{3. Результати та обговорення}

Для опису взаємодії зонної структури і поляризаційних ефектів у задачі Хартрі розглянуто структуру $\mathrm{GaN} / \mathrm{Al}_{0,3} \mathrm{Ga}_{0,7} \mathrm{~N}$ квантової ями шириною 2,6 і 3,9 нм. $\mathrm{Y}$ квантовій ямі, шириною 2,6 нм, при концентрації $9 \cdot 10^{12} \mathrm{~cm}^{-2}$, максимум оптичного підсилення дорівнює $23673,7 \mathrm{~cm}^{-1}$ на довжині хвилі $\lambda=334,5 \mathrm{Hм}$, тоді як при концентрації $7 \cdot 10^{12} \mathrm{~cm}^{-2}$, максимум оптичного підсилення дорівнює $14245,9 \mathrm{~cm}^{-1}$. Таке підсилення спостерігається на довжині хвилі $\lambda=336$ нм. $\mathrm{У}$ квантовій ямі, шириною 3,9 нм, при концентрації $9 \cdot 10^{12} \mathrm{~cm}^{-2}$ максимум оптичного підсилення дорівнює 5752,7 $\mathrm{cm}^{-1}$ на довжині хвилі $\lambda=348,3$ нм, тоді як при концентрації $7 \cdot 10^{12} \mathrm{~cm}^{-2}$ максимум оптичного підсилення дорівнюе $2840,8 \mathrm{~cm}^{-1}$. Таке підсилення обчислено на довжині хвилі $\lambda=352,1$ нм. Отже, оптичне підсилення $\mathrm{GaN} / \mathrm{Al}_{0,3} \mathrm{Ga}_{0,7} \mathrm{~N}$ у квантовій ямі розвивається в ультрафіолетовій області спектра, як показано на рис. 4.

Чисельно розв'язуючи рівняння Шредінгера (8), (12) для електронів і дірок та рівняння Пуассона (20), із стійких збіжних розв'язків можна побудувати квадрати хвильових функцій для важкої дірки (1), легкої дірки (2), наприклад, при поперечному хвильовому векторі $k_{t}=8 \cdot 10^{6} \mathrm{~cm}^{-1}$ і для електрона (3)
А; розподіл зарядової густини на ширині квантової ями (В); розподіл ефективного екрануючого електричного поля (C); квантовоямний потенціал і екрануючий потенціал на ширині квантової ями (D). Такі результати обчислень наведено для концентрації: $9 \cdot 10^{12}$ $\mathrm{cm}^{-2}$, для квантової ями 3,9 нм, див. рис. 1, 2, хартрівський спектр підсилення показано на рис. 4. Для вузької квантової ями можна побачити, що при концентраціі $7 \cdot 10^{12} \mathrm{~cm}^{-2}$ підсилення світла поступово розвивається зі збільшенням густини носіїв. При високій густині (тобто, коли густина дорівнює $9 \cdot 10^{12}$ $\mathrm{cm}^{-2}$ ) оптичне підсилення розвивається майже у спектральній області походження оптичного підсилення при густині плазми $7 \cdot 10^{12} \mathrm{~cm}^{-2}$.

Поведінка коефіцієнта підсилення світла для двох ширин квантової ями при заданих концентраціях може бути зрозуміла з досліджень, які наведено на рис. $1, a, b, 2, c, d$. Як видно з рис. 1, $a$, перекриття між електронною і дірковою хвильовими функціями пов'язані з розподілом зарядової густини на ширині квантової ями, що продемонстровано на рис. 1,b. Порівнюючи результати цих досліджень, можна прийти до висновку, що для широкої квантової ями інтеграл перекриття хвильових функцій менший, ніж у випадку вузької квантової ями, і зменшується сильніше при зменшенні густини носіїв.

Розподіл ефективного екрануючого електричного поля широкозонної квантової ями $\mathrm{GaN} / \mathrm{AlGaN}$, показаного на рис. 2,c, схоже на електричне поле в конденсаторі.

Як показано на рис. 4, ситуація відмінна в 3,9 нм $\mathrm{GaN} / \mathrm{Al}_{0,3} \mathrm{Ga}_{0,7} \mathrm{~N}$ структурі квантової ями. Оскільки квантовий конфайнмент у цій відносно широкій квантовій ямі слабкий, то п'єзоелектричне поле здатне значно зменшити інтеграл перекриття електронної і діркової хвильової функції, що можна побачити з порівняльних досліджень схожих до тих, які наведено на рис. 1, 2. Як наслідок, міжзонний дипольний матричний елемент або сила осцилятора є значно меншою, ніж у випадку вузької 2,6 нм квантової ями. Цей внутрішній ЕШКК теж здатен значно змістити в червоний бік максимум підсилення, що зв'язано 3 перенормуванням енергетичного спектра, при густині плазми $7 \cdot 10^{12} \mathrm{~cm}^{-2}$ відносно квантової ями 3 плоским дном. При зростанні густини плазми екранування ЕШКК приводить до зростання інтеграла перекриття електронно-діркової хвильової функції і, як наслідок - сили осцилятора. Одночасно це послаблене п'єзоелектричне поле, яке раніше індукувало червоне зміщення, тепер приводить до сітки голубих зміщень максимуму підсилення і краю поглина- 
ння при зростанні густини плазми, як показано на рис. 4.

Для обчислення концентраційних залежностей багаточастинкових кулонівських ефектів у спектрі поглинання GaN квантової ями застосовуємо підхід, схожий до методу, розвинутого у роботах $[14,33,34]$. Чисельно розв'язуючи мікроскопічне поляризаційне рівняння бачимо, що зі зростанням густини плазми оптичне підсилення (тобто негативне поглинання) розвивається у спектральній області походження екситонного резонансу. Зі зростанням густини вільних носіїв іонізаційний континуум швидко зміщується в бік довгих довжин хвиль, тоді як енергія $1 s$-екситонного рівня залишається майже сталою величиною. Це зумовлено високим ступенем компенсації між перенормуванням електричного дипольного моменту або енергією формування екситона і перенормуванням ширини забороненої зони, схоже як у дослідженнях для GaAs [35]. При високих електронно-діркових концентраціях ефект перенормування електричного дипольного моменту породжує велике оптичне підсилення, яке показане на рис. 5, 6. Максимум спектра хартрі-фокового підсилення 29991,2 $\mathrm{cm}^{-1}$ припадає на довжину хвилі $\lambda=339,1$ нм при концентрації $9 \cdot 10^{12} \mathrm{~cm}^{-2}$. Як видно 3 рис. 6 , хартрі-фоковий спектр зміщений у бік довгих довжин хвиль відносно спектра підсилення Хартрі і велике зоммерфельдівське або кулонівське підсилення присутне у квантовій ямі. Це зумовлено збільшенням сили осцилятора в результаті електрон-діркової кулонівської взаємодії притягання.

Розрахунок обмінного хартрі-фоківського перенормування енергетичного спектра враховується у рівнянні руху для мікроскопічного диполя, зумовленого електронно-дірковою парою. Для високих концентрацій ця величина є справді значною - трохи більшою для електронів і меншою для дірок. Сумарно ця величина відображається у зміщенні спектра хартріфоківського підсилення у порівнянні з хартрівським спектром, як показано на рис. 6. Слід зазначити, що у спектрі підсилення враховуються не лише хартріфоківські кореляції, а і кореляції вищих порядків розкладу за кулонівською потенціальною енергією, ніж хартрі-фоківські. Це досягається підсумовуванням ряду в мікроскопічному поляризаційному рівнянні за кулонівською енергією у всіх порядках теорії збурень. Докладно мікроскопічне поляризаційне рівняння для диполя, зумовленого електронно-дірковою парою для в'юрцитної квантової ями, буде розглядатися в нашій наступній статті.

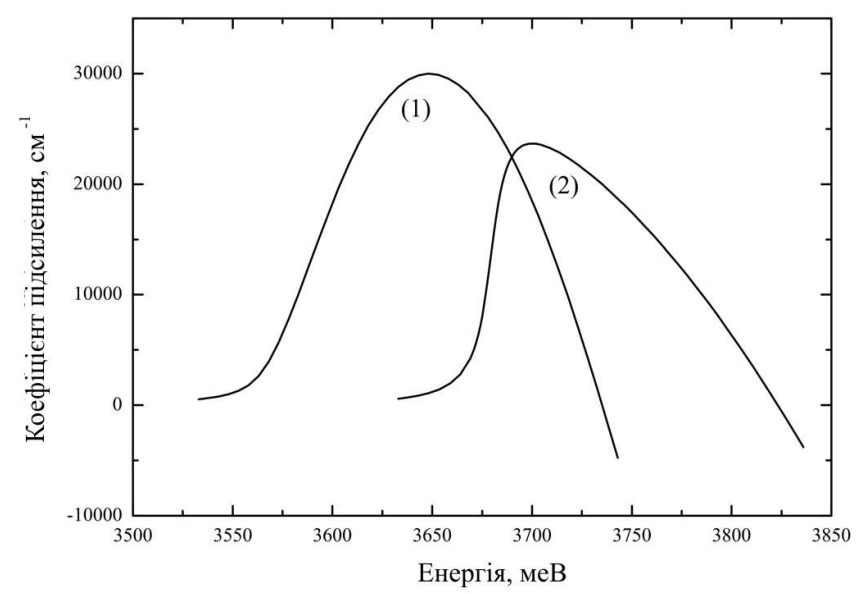

Рис. 6. Обчислений хартрі-фоківський спектр підсилення для квантової ями, шириною 2,6 нм, при концентраціях $n=p=$ $9 \cdot 10^{12} \mathrm{~cm}^{-2}(1)$ і Хартрівський спектр при концентрації $n=$ $p=9 \cdot 10^{12} \mathrm{~cm}^{-2}(2)$

\section{4. Висновки}

Підсумовуючи отримані результати, можна прийти до висновку, що самоузгоджене розв'язання рівнянь Шредінгера і рівняння Пуассона для широкозонних GaN/AlGaN систем квантових ям передбачають цікаві залежності від ширини квантової ями і густини зарядів як для матричних елементів електричного дипольного моменту міжзонних переходів, так і для спектра підсилення світла. Голубе зміщення зі зростанням густини плазми в спектрі підсилення у відносно широкій квантовій ямі здійснюється як наслідок екранування п'єзоелектричного поля, індукованого ЕШКК. Структури $з$ вузькою шириною ями проявляють звичайну залежність розвитку максимуму підсилення світла, без зміщення спектральної області. Знайдено, що матричні елементи оптичних переходів 3 важкої діркової підзони, подібно до спектра підсилення світла, мають строго ТЕ поляризацію світла. Знайдено червоне зміщення спектра оптичного підсилення Хартрі-Фока з урахуванням кулонівської взаємодії відносно спектра підсилення Хартрі. Також знайдено велике зоммерфельдівське підсилення у квантовій ямі.

Автор висловлює щиру подяку професору В.І. Шека та професору В.О. Кочелапу за численні дискусії.

1. S. Nakamura and G. Fasol The Blue Laser Diode (Springer, Berlin, 1997); R.L. Aggarwal, P.A. Maki, Z.-L. Liau, and I. Melngailis, J. Appl. Phys. 79, 2148 
(1996); S. Nakamura, M. Senoh, S. Nagahama, N. Iwasa, T. Yamada, T. Matsushita, H. Kiyoku, and Y. Sugimoto, Jpn. J. Appl. Phys. 1 35, L74 (1996); S. Nakamura, J. Vac. Sci. Technol. A 13, 705 (1995).

2. N. Savage, Nature Photonics 1, 83 (2007).

3. A. Khan, K. Balakrishnan, and T. Katona, Nature Photonics 2, 77 (2008).

4. Y. Taniyasu, M. Kasu, and T. Makimoto, Nature Letters 441, 325 (2006).

5. A.H. Mueller, M.A. Petruska, M. Achermann, D.J. Werder, E.A. Akhadov, D.D. Koleske, M.A. Hoffbauer, and V.I. Klimov, NanoLetters 5, 1039 (2005).

6. T. Wang, S. Wu, K.B. Lee, J. Bai, P.J. Parbrook, R.J. Airey, Q. Wang, G. Hill, F. Ranalli, and A.G. Gullis, Appl. Phys. Lett. 89, 081126 (2006).

7. B.F. Chu-Kung, M. Feng, G. Walter, N. Holonyak, jr., T. Chung, J. -H. Ryou, J. Limb, D. Yoo, S.-C. Shen, R.D. Dupuis, D. Keogh, and P.M. Asbeck, Appl. Phys. Lett. 89, 082108 (2006).

8. H. Hirayama, J. Appl. Phys. 97, 091101 (2005).

9. T. Asano, M. Takeya, T. Mizuno, S. Ikeda, K.K. Shibuya, T. Hino, S. Uchida, and M. Ikeda, Appl. Phys. Lett. 80, 3497 (2002).

10. S.-N. Lee, S.Y. Cho, H.Y. Ryu, J.K. Son, H.S. Paek, T. Jang, K.K. Choi, K.H. Ha, M.H. Yang, O.H. Nam, Y. Park, and E. Yoon, Appl. Phys. Lett. 88, 111101 (2006).

11. L.L. Gaddard, S.R. Bank, M.A. Wistey, H.B. Yuen, Z. Rao, and J.S. Harris, jr., J. Appl. Phys. 97, 083101 (2005).

12. E. Feltin, D. Simeonov, J.-F. Carlin, R. Butte, and N. Grandjean, Appl. Phys. Lett. 90, 021905 (2007).

13. H. Yoshida, Y. Yamashita, M. Kuwabara, and H. Kan, Nature Photonics 2, 551 (2008).

14. W. Chow, M. Kira, and S.W. Koch, Phys. Rev. B 60, 1947 (1999).

15. S.L. Chuang, J. Quantum Electron. 32, 1791 (1996).

16. W.W. Chow and M. Kneissl, J. Appl. Phys. 98, 114502 (2005).

17. J. Wang, J.B. Jeon, Yu.M. Sirenko, and K.W. Kim, Photonics Technology Lett. 9, 728 (1997).

18. E.I. Rashba, [Sov. Phys. Solid State 1, 368 (1959)] Fiz. Tverd. Tela 1, 407 (1959); E.I. Rashba and V.I. Sheka, ibid., Collection of Papers, 162 (1959); G.E. Pikus, ZhETF 41, 1258 (1961) Sov. Phys. JETP 14, 898 (1962).

19. G.L. Bir and G.E. Pikus, Symmetry and Strain-Induced Effects in Semiconductors (Wiley, New York, 1974).

20. P.Y. Yu and M. Cardona, Fundamentals of Semiconductors (Springer, Berlin, 1996).

21. Yu.M. Sirenko, J.-B. Jeon, K.W. Kim, M.A. Littlejohn, and M.A. Stroscio, Phys. Rev. B 53, 1997 (1996).

22. R.G. Banal, M. Funato, and Y. Kawakami, Phys. Rev. B 79, 121308(R) (2009).

23. L.D. Landau, E.M. Lifshitz, Quantum Mechanics (Pergamon, Oxford, 1977).

24. G. Bastard, E.E. Mendez, L.L. Chang, and L. Esaki, Phys. Rev. B 28, 3241 (1983).

25. I. Vurgaftman, J.R. Meyer, and L.R. Ram-Mohan, J. Appl. Phys. 89, 5815 (2001).

26. Semiconductors, edited by O. Madelung (Springer, Berlin, 1991); W. Shan, T.J. Schmidt, X.H. Yang, S.J. Hwang, J.J. Song, and B. Goldenberg, Appl. Phys. Lett. 66, 985 (1995).

27. Yu.M. Sirenko, J.-B. Jeon, B.C. Lee, K.W. Kim, M.A. Littlejohn, M.A. Stroscio, and G.I. Iafrate, Phys. Rev. B 55, 4360 (1997).

28. S.L. Chuang and C.S. Chang, Phys. Rev. B 54, 2491 (1996).

29. M. Suzuki, T. Uenoyama, and A. Yanase, Phys. Rev. B 52, 8132 (1995).

30. S.L. Chuang, C.S. Chang, and A. Yanase, Phys. Rev. B 54, 2491 (1996).

31. V.V. Mitin, V.A. Kochelap, and M.A. Stroscio, Quantum Heterostructures (Cambridge Univ. Press, New York, 1999).

32. L.O. Lokot, Semicon. Phys. Quantum Electron. Optoelectron. 11, 364 (2008); L.O. Lokot, Ukr. Fiz. Zh. 54, 964 (2009).

33. M. Lindberg and S.W. Koch, Phys. Rev. B 38, 3342 (1988).

34. W.W. Chow, S.W. Koch, and M. Sargent III, Semiconductor Laser Physics (Springer, New York, 1994).

35. H. Haug and S. Schmitt-Rink, Prog. Quant. Electr. 9, 3 (1984).

Одержано 11.04.2011 


\section{ОПТИЧЕСКАЯ ПОЛЯРИЗАЦИОННАЯ АНИЗОТРОПИЯ, ВНУТРЕННИЙ ЭФФЕКТ ШТАРКА КВАНТОВОГО КОНФАЙНМЕНТА И ВЛИЯНИЕ КУЛОНОВСКИХ ЭФФЕКТОВ НА ЛАЗЕРНЫЕ ХАРАКТЕРИСТИКИ [0001]-ОРИЕНТИРОВАННЫХ GaN $/ \mathrm{Al}_{0,3} \mathrm{Ga}_{0,7} \mathrm{~N}$ КВАНТОВЫХ ЯМ}

\section{Л.Е. Локоть}

$\mathrm{P}$ е $з$ ю м е

Представлено теоретическое исследование пространственно разделенных электронных и дырочных распределений при самосогласованном решении уравнений Шредингера для электронов и дырок и уравнения Пуассона. Результаты проиллюстрированы для $\mathrm{GaN} / \mathrm{Al}_{0,3} \mathrm{Ga}_{0,7} \mathrm{~N}$ квантовой ямы. Спектр оптического усиления для [0001]-ориентированной $\mathrm{GaN} / \mathrm{Al}_{0,3} \mathrm{Ga}_{0,7} \mathrm{~N}$ квантовой ямы был вычислен в ультрафиолетовой области. Найдено, что как матричные элементы оптических переходов с тяжелой дырочной подзоны в зону проводимости, так и спектр оптического усиления характеризуются именно $x$ (или $y$ ) поляризацией света. Показано влияние конфайнмента волновых функций на оптическое усиление, которое неявно зависит от встроенного электрического поля, которое вычислено и равно $2,3 \mathrm{MB} / \mathrm{cм}$. Если структуры с узкой шириной ямы проявляют обычную зависимость развития максимума усиления света почти без смещения спектральной области, то структуры с большой шириной квантовой ямы характеризуются значительным голубым смещением максимума усиления с ростом плотности плазмы. Это голубое смещение относят к взаимодействию между экранирующим пьезоэлектрическим полем, создаваемым деформацией и зонной структурой. В квантовой яме присутствует значительное зоммерфельдовское или кулоновское усиление.
OPTICAL POLARIZATION ANISOTROPY, INTRINSIC

STARK EFFECT AND COULOMB EFFECTS

ON THE LASING CHARACTERISTICS

OF [0001]-ORIENTED GaN/ $\mathrm{Al}_{0.3} \mathrm{Ga}_{0.7} \mathrm{~N}$ QUANTUM WELLS

\section{L.O. Lokot}

V. Lashkaryov Institute of Semiconductor Physics, Nat. Acad. of Sci. of Ukraine

(41, Prosp. Nauky, Kyiv 03028, Ukraine;

e-mail: llokot@gmail.com)

$\mathrm{S}$ u $\mathrm{m}$ m a r y

We present a theoretical investigation of space separated electron and hole distributions, which consists in the self-consistent solving of the Schrödinger equations for electrons and holes and the Poisson equation. The results are illustrated for the GaN/ $\mathrm{Al}_{0.3} \mathrm{Ga}_{0.7} \mathrm{~N}$ quantum well. The optical gain spectrum in a [0001]-oriented $\mathrm{GaN} / \mathrm{Al}_{0.3} \mathrm{Ga}_{0.7} \mathrm{~N}$ quantum well in the ultraviolet region is calculated. It is found that both the matrix elements of optical transitions from the heavy hole band and the optical gain spectrum have only the strict $x$ (or $y$ ) light polarization. We present studies of the influence of the confinement of wave functions on the optical gain which implicitly depends on the built-in electric field calculated to be $2.3 \mathrm{MV} / \mathrm{cm}$. Whereas the structures with narrow well widths exhibit the usual development of the light gain maximum almost without shifting the spectral region, a significant blueshift of the gain maximum is found with increase in the plasma density for wider quantum wells. This blueshift is ascribed to the interplay between the screening of a strain-induced piezoelectric field and the bandstructure. A large Sommerfeld or Coulomb enhancement is present in the quantum well. 